\title{
Calcium-Dependent But Action Potential-Independent BCM-Like Metaplasticity in the Hippocampus
}

\author{
Sarah R. Hulme, Owen D. Jones, David R. Ireland, and Wickliffe C. Abraham \\ Brain Health Research Centre and Department of Psychology, University of Otago, Dunedin 9054, New Zealand
}

The Bienenstock, Cooper and Munro (BCM) computational model, which incorporates a metaplastic sliding threshold for LTP induction, accounts well for experience-dependent changes in synaptic plasticity in the visual cortex. BCM-like metaplasticity over a shorter timescale has also been observed in the hippocampus, thus providing a tractable experimental preparation for testing specific predictions of the model. Here, using extracellular and intracellular electrophysiological recordings from acute rat hippocampal slices, we tested the critical BCM predictions (1) that high levels of synaptic activation will induce a metaplastic state that spreads across dendritic compartments, and (2) that postsynaptic cell-firing is the critical trigger for inducing that state. In support of the first premise, high-frequency priming stimulation inhibited subsequent long-term potentiation and facilitated subsequent long-term depression at synapses quiescent during priming, including those located in a dendritic compartment different to that of the primed pathway. These effects were not dependent on changes in synaptic inhibition or NMDA/ metabotropic glutamate receptor function. However, in contrast to the BCM prediction, somatic action potentials during priming were neither necessary nor sufficient to induce the metaplasticity effect. Instead, in broad agreement with derivatives of the BCM model, calcium as released from intracellular stores and triggered by M1 muscarinic acetylcholine receptor activation was critical for altering subsequent synaptic plasticity. These results indicate that synaptic plasticity in stratum radiatum of CA1 can be homeostatically regulated by the cell-wide history of synaptic activity through a calcium-dependent but action potential-independent mechanism.

\section{Introduction}

There is considerable evidence that activity-dependent synaptic plasticity such as LTP and LTD serve as memory mechanisms. As expected of memory mechanisms, there is not a fixed synaptic plasticity response to a given activation pattern, but instead plasticity is dynamically influenced by a number of state variables, including the trace left by prior neural activity, i.e., metaplasticity (Abraham and Bear, 1996; Abraham, 2008). The need for metaplasticity has been demonstrated in computational and neural network models which indicate that there must be control over both the extent and timing of plasticity induction (Grossman et al., 2002; Yeung et al., 2004). For example, the Bienenstock, Cooper and Munro (BCM) (Bienenstock et al., 1982) computational model of synaptic plasticity incorporates a parameter termed the modification threshold, $\theta_{\mathrm{M}}$, that dynamically varies with the history of prior postsynaptic cell firing, thereby homeostatically regulating the direction and degree of subsequent synaptic plasticity. Thus, following a period of increased cell activity, LTP becomes harder to induce and LTD more likely; conversely, a period of reduced activity has the opposite effect.

Received Feb. 9, 2012; revised March 15, 2012; accepted March 19, 2012.

Author contributions: S.R.H. and W.C.A. designed research; S.R.H., O.D.J., and D.R.I. performed research; S.R.H., O.D.J., and D.R.I. analyzed data; S.R.H. and W.C.A. wrote the paper.

This research was supported by a grant from the New Zealand Marsden fund to W.C.A., a postgraduate scholarship from the University of Otago to S.R.H., and a Neurological Foundation of New Zealand W.B. Miller postgraduate scholarship to 0.D.J.

The authors declare no competing financial interests.

Correspondence should be addressed to Sarah R. Hulme, Brain Health Research Centre and Department of Psychology, University of Otago, P0 Box 56, Dunedin 9054, New Zealand. E-mail: hulme@psy.otago.ac.nz.

DOI:10.1523/JNEUROSCI.0634-12.2012

Copyright $\odot 2012$ the authors $\quad 0270-6474 / 12 / 326785-10 \$ 15.00 / 0$
The activity-dependent regulation of $\theta_{\mathrm{M}}$ in the BCM model is a form of metaplasticity (Abraham and Bear, 1996; Abraham, 2008) for which two key characteristics are posited: (1) it is calculated from a running time-average of postsynaptic action potential activity, and (2) it affects excitatory synapses throughout the cell (Bienenstock et al., 1982). However, recent variants of the BCM model have focused on the time-averaged intracellular free calcium concentration, or activity of a downstream enzyme such as calcium-dependent protein kinase II, as the biological signal that metaplastically controls the plasticity induction (Shouval et al., 2002a,b; Yeung et al., 2004).

BCM-like changes in plasticity induction account well for a variety of phenomena, including experience-dependent changes in visual and somatosensory neural activity (Benusková et al., 1994; Kirkwood et al., 1996; Philpot et al., 2003, 2007) and synaptic plasticity in the dentate gyrus (Benuskova and Abraham, 2007). BCM-like metaplasticity effects over a shorter timescale have also been observed in the hippocampus, providing a tractable experimental preparation for testing the two key postulates noted above. Because initial tests have been made using field potential recording techniques in the hippocampus (Wang and Wagner, 1999; Abraham et al., 2001), the precise role played by postsynaptic action potentials, for example, remains uncertain. Here we used the heterosynaptic metaplasticity experimental protocols established by Wang and Wagner (1999) as the starting point for making these tests. We found that repeated HFS caused a BCM-like shift in the plasticity induction function that could spread across the dendritic arbor of CA1 hippocampal pyramidal cells. Surprisingly, action potential generation was neither necessary nor sufficient for activity-dependent suppression of LTP, in 
contrast to the assumption of the original BCM model. Rather, in broad accord with calcium-focused derivatives of the model (Yeung et al., 2004), a calcium signal arising through release from intracellular stores, as triggered by M1 muscarinic acetylcholine receptor activation, mediated the metaplasticity effects.

\section{Materials and Methods}

Tissue preparation. Young adult male Sprague-Dawley rats (6-8 weeks old) were anesthetized with ketamine $(100 \mathrm{mg} / \mathrm{kg}$, i.p.) and decapitated. Brains were then submersed in ice-cold sucrose dissection solution (containing, in mm: 210 sucrose, $26 \mathrm{NaHCO}_{3}, 2.5 \mathrm{KCl}, 1.25 \mathrm{NaH}_{2} \mathrm{PO}_{4}, 0.5$ $\mathrm{CaCl}_{2}, 3 \mathrm{MgCl}_{2}$, and $20 \mathrm{D}$-glucose) or in artificial CSF (ACSF, containing, in mM: $124 \mathrm{NaCl}, 3.2 \mathrm{KCl}, 1.25 \mathrm{NaH}_{2} \mathrm{PO}_{4}, 26 \mathrm{NaHCO}_{3}, 2.5 \mathrm{CaCl}_{2}, 1.3$ $\mathrm{MgCl}_{2}$, and 10 D-glucose) equilibrated with carbogen $\left(95 \% \mathrm{O}_{2}-5 \% \mathrm{CO}_{2}\right)$. Transverse hippocampal slices $(400 \mu \mathrm{m})$ were prepared and transferred to a humidified submersion brain slice chamber. ACSF was continuously superfused $(2 \mathrm{ml} / \mathrm{min})$ by gravity feed and slices were allowed to equilibrate for at least $3 \mathrm{~h}$ before baseline recordings began, while the temperature was gradually brought to $32.5^{\circ} \mathrm{C}$.

Extracellular recording techniques. Synaptic potentials were evoked through stimulation of the Schaffer collateral-commissural pathway in stratum radiatum, and in some experiments stratum oriens, of area CA1 using $50 \mu \mathrm{m}$ Teflon-insulated tungsten monopolar electrodes. Pulse half-wave duration was $0.1 \mathrm{~ms}$. Recordings from the same stratum that was stimulated were made using glass micropipettes filled with $2 \mathrm{M} \mathrm{NaCl}$ (1-2 M $\Omega$ ). In experiments using two stimulating electrodes in stratum radiatum, the electrodes were placed equidistant from the single recording electrode, on either side and at a similar central position in stratum radiatum. In the experiments where both stratum radiatum and stratum oriens were stimulated, two recording and two stimulating electrodes were used. These were arranged with the recording electrodes in line and perpendicular to the cell-body layer, to record from the same population of cells, while both stimulating electrodes were positioned on the same side of the recording electrodes. The criterion for use of a slice in an experiment was that the fEPSP responses for each pathway were $2 \mathrm{mV}$ or greater at a stimulation intensity of $100 \mu \mathrm{A}$. Stimulation intensity was then adjusted to elicit a $1 \mathrm{mV}$ response $(25-70 \mu \mathrm{A})$. Baseline stimulation was delivered every $30 \mathrm{~s}$, alternating between stimulating electrodes. Priming stimulation was given on one pathway (radiatum or oriens), using a protocol that consisted of two sets of three $100 \mathrm{~Hz}, 1 \mathrm{~s}$ trains $(20$ $\mathrm{s}$ between trains, 5-15 min between sets). Conditioning stimulation to induce plasticity was given on a second test pathway (always in stratum radiatum, unless otherwise noted) $30 \mathrm{~min}$ after priming. The conditioning protocol consisted of two trains of 600 pulses at stimulation frequencies of $10,20,50$ or $100 \mathrm{~Hz}$ (10 min between trains) for initial experiments or a more standard LTP induction protocol of two $100 \mathrm{~Hz}$ $1 \mathrm{~s}$ trains ( $30 \mathrm{~s}$ between trains).

Intracellular recording techniques. Because of the long duration of the experiments, and the consequent high probability of washout of biochemicals essential for LTP on the test pathway, single-cell recordings for LTP studies were made using intracellular sharp electrode techniques, rather than whole-cell patch-clamp methods. Synaptic potentials were evoked as for extracellular experiments using either two stimulating electrodes in stratum radiatum, or one each in strata radiatum and oriens. Intracellular recordings, using borosilicate micropipettes filled with $2 \mathrm{M}$ KAc (1.0 mm outside diameter and $0.5 \mathrm{~mm}$ inside diameter; Sutter Instrument Co., 80-140 M $\Omega$ ), were made in current-clamp mode from CA1 pyramidal cells. The criteria for use in an experiment were that a cell had a resting membrane potential of $\leq-60 \mathrm{mV}$, showed overshooting action potentials when depolarized and exhibited an input resistance $\left(R_{\text {in }}\right)>30 \mathrm{M} \Omega$. A further criterion was that at $-75 \mathrm{mV}$ the EPSP amplitude was $\geq 8 \mathrm{mV}$ with single pulse stimulation of $100 \mu \mathrm{A}$. For the experiments, the stimulation intensity was adjusted to produce a response consistently $>5$ but $<8 \mathrm{mV}(35-90 \mu \mathrm{A})$. The membrane potential of impaled cells was held constant at $-75 \mathrm{mV}$ during the baseline periods and depolarized to an initial $-60 \mathrm{mV}$ (radiatum-radiatum experiments) or $-65 \mathrm{mV}$ (oriens-radiatum experiments) during priming and conditioning stimulation by manually adjusting the holding current.
Pathway independence. To confirm the independence of the two pathways, a paired-pulse stimulation test (50 ms interpulse interval) was used for all experiments. When the two pulses were given to the same pathway, paired-pulse facilitation (PPF) was observed. Experiments were excluded if PPF following the same-electrode stimulation was not $>10 \%$. When pulses were given to alternate pathways no slices showed crossfacilitation $>10 \%$, indicating pathway independence.

Data analysis. The initial slopes of the fEPSPs and EPSPs were analyzed as a measure of synaptic efficacy. Baseline was calculated as the average response over the $10 \mathrm{~min}$ before conditioning. All response measurements were converted to a percentage of baseline. LTP was calculated as the average over the last 5 or $10 \mathrm{~min}$ of recording for extracellular and intracellular experiments, respectively. All group data are presented as mean \pm SEM. Note that data are typically presented only for the heterosynaptic stratum radiatum test pathway (S2, Figs. $1 A, 2 A$, insets). Priming stimulation (either in radiatum or oriens) routinely induced LTP homosynaptically. Unless otherwise noted statistical analysis for significant differences between control and primed groups was assessed by Student's $t$ test or ANOVA (one-way or repeated measures with Greenhouse-Geisser corrected values, as appropriate). The critical value was set at $p<0.05$.

Whole-cell recordings techniques. To assess the effects of priming stimulation on NMDA receptor-mediated currents, hippocampal slices for wholecell patch-clamp recordings were prepared as previously described (Ireland and Abraham, 2009). Standard techniques were used to record EPSCs from the soma of visualized CA1 pyramidal neurons. Patch electrodes were formed from soft borosilicate glass (WPI) and had resistances of 2-3 M $\Omega$ when filled with a K-based recording solution (containing, in mM: 140 $\mathrm{KMeSO}_{4}, 10 \mathrm{HEPES}, 4 \mathrm{Na}_{2} \mathrm{ATP}, 0.4 \mathrm{NaGTP}, 4 \mathrm{MgCl}_{2}, \mathrm{Na}_{2}$ phosphocreatine, 0.2 EGTA-4Na, 1 QX-314, pH 7.25 when adjusted with $\mathrm{KOH}, \sim 320 \mathrm{mOsm}$ when adjusted with sucrose). Access resistance was continuously monitored throughout each experiment (10-20 M $\Omega$ at beginning of experiment) and experiments that differed from baseline values by $>30 \%$ were discarded. EPSCs were evoked by electrical stimulation of Schaffer collateral fibers in stratum radiatum, and stratum oriens fibers, via broken off patch-electrodes filled with ACSF. EPSCs composed of currents mediated by both NMDA receptors and AMPA receptors (EPSCs NMDAR/AMPAR $_{\text {N }}$ ) were isolated by inhibiting $\mathrm{GABA}_{\mathrm{A}}$ and $\mathrm{GABA}_{\mathrm{B}}$ receptors with bath-applied picrotoxin (20 $\mu \mathrm{M})$ and CGP55845 $(1 \mu \mathrm{M})$, respectively. EPSCs mediated solely by NMDARs (EPSCs ${ }_{\text {NMDAR }}$ ) were isolated by the further addition of CNQX $(10 \mu \mathrm{M})$. In all experiments, voltage-dependent calcium currents mediated by L-type channels were inhibited with bath-applied nimodipine $(10 \mu \mathrm{M})$. All EPSCs were recorded in voltage-clamp mode at a holding potential of $-30 \mathrm{mV}$ using an Axopatch 1D amplifier and pCLAMP 9 software (Molecular Devices). They were sampled at $10 \mathrm{kHz}$ and filtered at $2 \mathrm{kHz}$. Baseline stimulation (oriens and radiatum pathways) evoking single EPSC $s_{\text {NMDAR/AMPAR, }}$, priming stimulation delivered to stratum oriens, and stratum radiatum conditioning stimulation $(100 \mathrm{~Hz})$ evoking summated $\mathrm{EPSCs}_{\mathrm{NMDAR}}$, were delivered with the same frequencies and intervals as in the sharp electrode intracellular recording experiments. Stratum oriens priming stimulation was delivered in current-clamp mode at a holding potential of $-60 \mathrm{mV}$.

Patch-clamp data analysis. Raw data were analyzed using pCLAMP 9 software. The amplitude of the NMDAR-mediated component of the EPSC $_{\text {NMDAR/AMPAR }}$ was measured at a fixed point on the EPSC after the AMPAR-mediated component had decayed. Peak amplitude and area

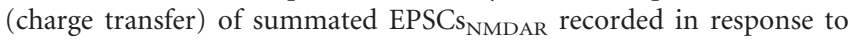
stratum radiatum conditioning stimulation were normalized to the amplitude and area of single EPSCs $s_{\text {NMDAR }}$. Differences between the datasets were analyzed with unpaired Student's $t$ tests at the $p<0.05$ significance level. Data are reported as mean \pm SEM.

Drugs and reagents. All salts were obtained from BDH Laboratory Supplies. Drugs, including D-AP5, nimodipine, LY341495, CGP55845, CNQX, picrotoxin, QX-314, pirenzepine dihydrochloride, and cyclopiazonic acid (CPA), were obtained from Tocris Bioscience. $\mathrm{Na}_{2} \mathrm{ATP}$, NaGTP, phosphocreatine, and EGTA-4Na were obtained from Sigma. $\mathrm{KMeSO}_{4}$ was obtained from Acros Organics. Xestospongin C was obtained from Cayman Chemical. AP5 and pirenzepine were dissolved in $\mathrm{H}_{2} \mathrm{O}$. Nimodipine, xestospongin $\mathrm{C}$, and cyclopiazonic acid were dissolved in DMSO and LY341495 was dissolved in $\mathrm{NaOH}$ ( $\mathrm{pH}$ adjusted to 7 with $\mathrm{HCl}$ ). Drugs were diluted by $\geq 500$-fold and introduced into the 

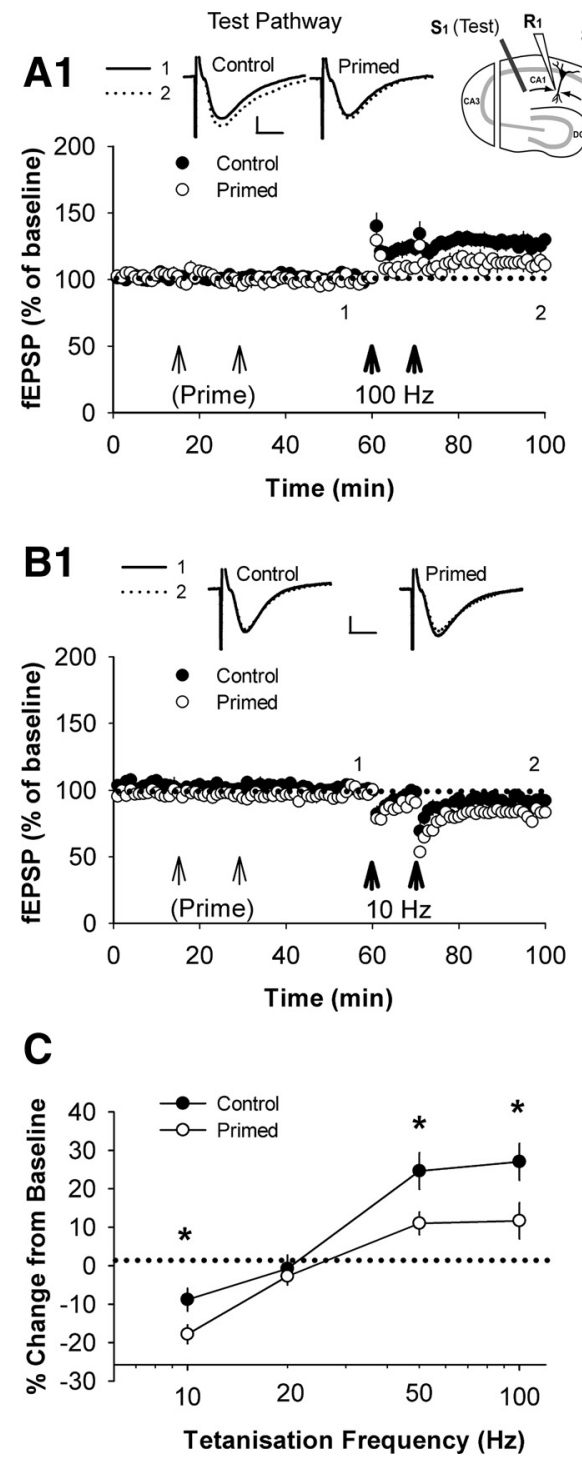

Figure 1. BCM-like heterosynaptic priming of LTP and LTD in stratum radiatum. Diagram of a hippocampal slice with electrode configurations shown. S1, Pathway on which priming stimulation was delivered; S2: pathway on which conditioning was delivered; R1, recording electrode. A1, When high-frequency priming stimulation was delivered on one radiatum pathway (light arrows, data for the primed pathway shown in $\mathbf{A 2}$ ), the level of LTP induced by subsequent $100 \mathrm{~Hz}$ stimulation (dark arrows) on the test pathway was significantly reduced (control, $27 \pm 5 \%, n=8$; primed, $12 \pm 5 \%, n=6 ; p=0.046$ ). B1, Under control conditions $10 \mathrm{~Hz}$ conditioning induced stable LTD $(-9 \pm 3 \% ; n=6)$. In primed slices (data for the primed pathway shown in B2) significantly greater LTD of $-18 \pm 2 \%$ was induced $(n=7 ; p=0.025)$. Insets, Representative waveforms are averages of 5 synaptic responses before LTP induction (1) and at the conclusion of the experiment (2). Calibration: $0.5 \mathrm{mV}, 10 \mathrm{~ms}$. C, Summary plot of mean fEPSP slope in the last 5 min of recording expressed as percentage change from baseline for control (filled circles) and primed (unfilled circles) groups across the range of stimulation frequencies from 10 to $100 \mathrm{~Hz}$. Asterisks indicate significant difference between groups. $\boldsymbol{D}$, Conditioning stimulation at $10 \mathrm{~Hz}$ with stronger stimulation $(1.5 \mathrm{mV})$ induces a small potentiation which can be converted to depression when priming has been previously given (control, $6 \pm 3 \%, n=9$; primed, $-5 \pm 4 \%, n=$ $6 ; p=0.044$ ). Inset, Summary plot showing the shift in LTD/LTP crossover point observed when stronger stimulation is used to induce synaptic plasticity. All data in this and subsequent figures are expressed as mean \pm SEM.

ACSF through bath application. In experiments where the drug was dissolved in DMSO, control experiments were also exposed to DMSO during the corresponding time points.

\section{Results}

Priming stimulation heterosynaptically inhibits LTP and promotes LTD

We first aimed to confirm that the Wang and Wagner (1999) priming protocol reliably produced in our hands a BCM-like heterosynaptic regulation of plasticity at Schaffer collateral synapses in area
CA1. Under control conditions, $100 \mathrm{~Hz}$ and $50 \mathrm{~Hz}$ conditioning stimulation induced stable LTP, $20 \mathrm{~Hz}$ conditioning did not change responses on average, and $10 \mathrm{~Hz}$ stimulation evoked LTD (Fig. $1 A 1, B 1$, control). As predicted, prior $100 \mathrm{~Hz}$ priming stimulation of a second stratum radiatum pathway (Fig. 1A2,B2) inhibited LTP and facilitated LTD induced $30 \mathrm{~min}$ later on the test pathway (Fig. $1 A 1, B 1$, primed). These results demonstrate that, in accordance with both the BCM model and previous results, a high level of prior activity can heterosynaptically inhibit LTP and facilitate LTD induced at synapses quiescent during the priming activity. Interestingly, there was no significant correlation between the magnitude of priming-induced LTP and the level of LTP/LTD subsequently induced on the test pathway (10 Hz group: $r=-0.169, p=$ 0.72; $100 \mathrm{~Hz}$ group: $r=0.095, p=0.86$ ).

Surprisingly, the response near the LTD/LTP crossover point ( $\theta_{\mathrm{M}}$ of the BCM model) evoked by $20 \mathrm{~Hz}$ conditioning stimulation was only weakly shifted by the priming stimulation (Fig. 1C). To understand the lack of change at the LTD/LTP crossover point, we considered the possibility that our relatively weak stimulation strength used for conditioning stimulation may have resulted in a right-shifted crossover point under control conditions, making it difficult to shift it further with priming stimulation (compare our Fig. $1 C$ with Wang and Wagner, 1999, their Fig. 3). To address this point, we increased the stimulation strength during the conditioning stimulation to one which elicited a $1.5 \mathrm{mV}$ fEPSP, and found that it moved the crossover point from $\sim 20 \mathrm{~Hz}$ to $<10 \mathrm{~Hz}$. Priming stimulation was then able to shift the crossover point to the right, in accord with the BCM model (Fig. $1 D)$. All further experimentation was undertaken using the original conditioning stimulation strength, focusing on $100 \mathrm{~Hz}$ and $10 \mathrm{~Hz}$ stimulation for studies of LTP and LTD, respectively.

\section{Heterosynaptic metaplasticity can occur cell-wide}

In the above experiments we demonstrated BCM-like heterosynaptic interactions between independent sets of synapses terminating in a common dendritic field, i.e., the stratum radiatum. However, the BCM model predicts that prior activity will regulate the plasticity function of excitatory synapses throughout the cell. Since it was conceivable that the heterosynaptic metaplasticity in the present study only affected synapses located near the primed ones (Chevaleyre and Castillo, 2004), we tested the cell-wide nature of the present effect by giving priming stimulation either in the stratum oriens (basilar dendrites) or stratum radiatum (apical dendrites) and subsequently inducing LTP or LTD on the other side of the cell 

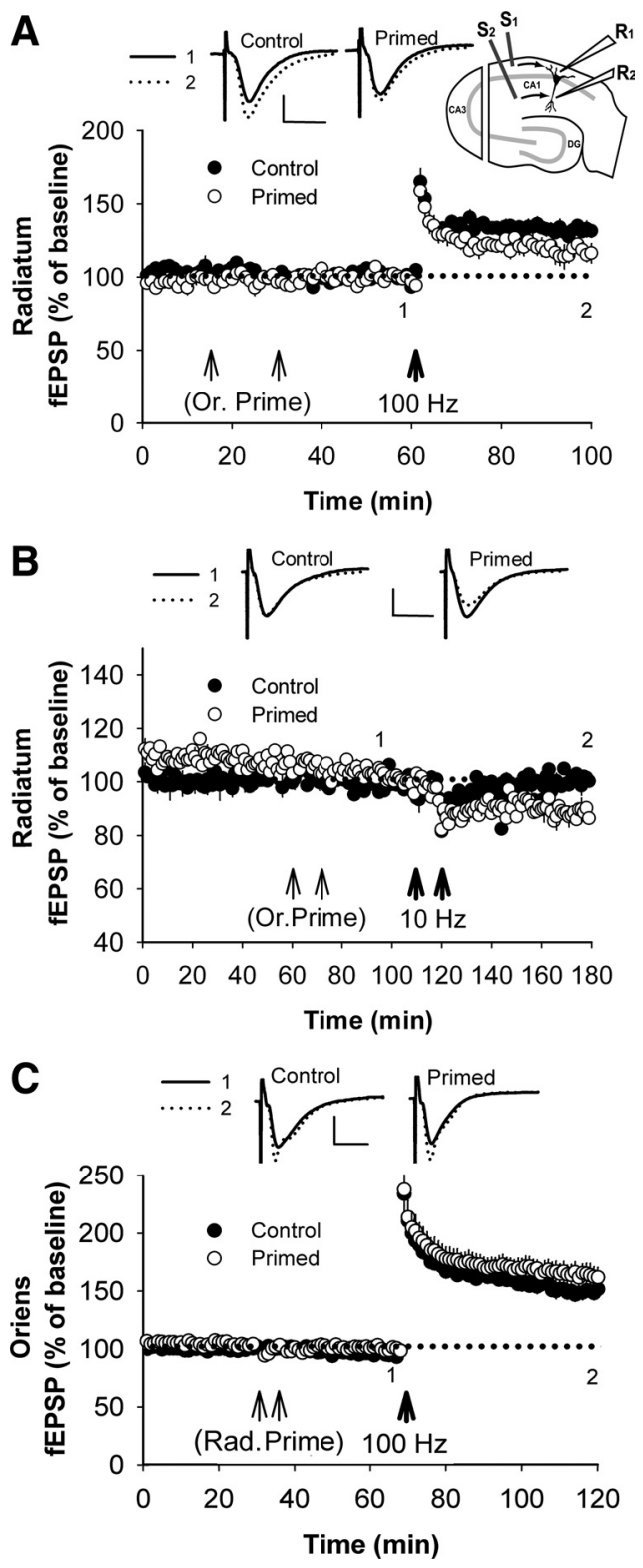

Figure 2. The metaplastic state can be cell-wide or compartmentally restricted. Diagram of a hippocampal slice with electrode configurations shown for $\boldsymbol{A}$ and $\boldsymbol{B}$. S1, Stratum oriens pathway on which priming stimulation was delivered; $\$ 2$, stratum radiatum pathway on which conditioning was delivered; $R 1$, recording electrode in stratum oriens; $R 2$, recording electrode in stratum radiatum. $\boldsymbol{A}$, When high-frequency priming stimulation was delivered to stratum oriens (light arrows), the level of LTP induced by subsequent $100 \mathrm{~Hz}$ stimulation (dark arrow) on the test pathway in stratum radiatum was significantly reduced (control, $n=6$; primed, $n=$ 6). $B$, Priming in stratum oriens also facilitated LTD induction in stratum radiatum (control, $1 \pm$ $1 \%, n=6$; primed, $-12 \pm 4 \%, n=6$ ). C, Priming stimulation in stratum radiatum did not inhibit LTP subsequently induced in stratum oriens (control, $n=8$; primed, $n=7$ ). Insets, Representative waveforms are averages of 5 synaptic responses before LTP induction (1) and at the conclusion of the experiment (2). Calibration: $0.5 \mathrm{mV}, 10 \mathrm{~ms}$.

bodies. We observed LTP in stratum radiatum $(30 \pm 3 \%)$ was reliably inhibited by the prior delivery of priming stimulation to afferents in stratum oriens ( $16 \pm 4 \%, p=0.02$; Fig. 2A). Correspondingly, LTD induced by low-frequency stimulation (LFS) was facilitated by priming stimulation ( $p=0.01$; Fig. $2 B$ ). In contrast, LTP induced in stratum oriens ( $42 \pm 5 \%$ ) was not inhibited by priming stimulation in stratum radiatum $(61 \pm 8 \%, p=0.20$; Fig. $2 C$ ). Increasing the intensity of the radiatum priming stimulation (to generate $1.5 \mathrm{mV}$ responses) still failed to inhibit oriens LTP (42 \pm
$7 \%, p=0.54$; data not shown). These results demonstrate that metaplastic changes induced using our paradigm are compartmentally restricted when priming is delivered to afferents in stratum radiatum but cell-wide when delivered to afferents in stratum oriens. We do not, however, rule out the possibility that other priming paradigms may be effective in generating radiatum to oriens interactions.

\section{Plasticity modification is not due to altered NMDAR currents or GABAergic transmission}

In extensions of the BCM model, the expression of metaplastic change has been modeled as an alteration in the function of NMDARs (Gold and Bear, 1994; Shouval et al., 2002b). For this reason we predicted that there would be a change evident in the NMDAR-mediated EPSC following priming. To directly assess this possibility, single EPSCs $s_{\text {NMDAR/AMPAR }}$ were recorded using whole-cell patch-clamp techniques. Note that AMPARs were not blocked at this stage to allow AMPAR-mediated depolarization to occur during the priming protocol, as would have occurred during the equivalent extracellular experiments. Following priming stimulation of stratum oriens (in current-clamp to allow cell depolarization), the amplitude of the NMDAR-mediated component of the EPSC $_{\text {NMDAR/AMPAR }}$ recorded on the same pathway (oriens) was indeed significantly reduced by $-27 \pm 8 \%(n=5$, $p=0.023$ compared with unprimed controls; Fig. $3 A$ ). However, the NMDAR component recorded in stratum radiatum in the same slices was not significantly altered $(4 \pm 7 \%, p=0.845$; Fig. $3 B)$. Note that since LTD of the EPSC NMDAR/AMPAR $_{\text {did occur }}$ homosynaptically in oriens synapses, it is unlikely that the lack of change in radiatum responses is due to washout of any biochemicals critical for inducing NMDAR change, as mediated by our whole-cell recording conditions.

Although the amplitudes of baseline radiatum NMDAR-mediated EPSCs were not changed by oriens priming stimulation, there may still have been a change in the summated EPSC $_{\text {NMDAR }}$ produced by radiatum conditioning stimulation for LTP induction. To address this issue, immediately at the conclusion of the previous experiment CNQX was applied to isolate the NMDAR-mediated EPSC and then the standard LTP induction protocol (2 trains of $100 \mathrm{~Hz}, 1 \mathrm{~s}, 30 \mathrm{~s}$ between trains) was applied to the stratum radiatum pathway. Sum-

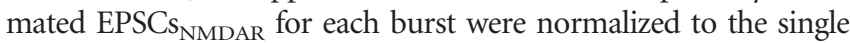
EPSCS $_{\text {NMDAR }}$ recorded during the 5 min before conditioning stimulation. There was no difference between control and primed cells for the summated EPSC $_{\mathrm{NMDAR}}$ amplitudes or areas recorded during either the first or second HFS burst (Fig. 3C,D). Together these results indicate that a change in NMDAR function is not the mechanism by which the heterosynaptic metaplasticity is expressed.

An alternative mechanism by which priming could produce a very long-range effect is through a persistent facilitation of transmission at GABAergic synapses, or facilitated activation of GABAergic interneurons, consequently increasing synaptic inhibition on the heterosynaptic pathway during conditioning stimulation thus blocking LTP. To test this possibility, $\mathrm{GABA}_{\mathrm{A}}$ and $\mathrm{GABA}_{\mathrm{B}}$ receptor-mediated inhibition was blocked with $100 \mu \mathrm{M}$ picrotoxin and $1 \mu \mathrm{M}$ CGP55845, respectively, for the duration of the experiment. The priming stimulation and conditioning stimulation were given to separate stratum radiatum pathways, as per the methods of the previous extracellular experiments. The conditioning protocol for LTP induction, however, was reduced to 600 pulses at $50 \mathrm{~Hz}$ due to the increased slice excitability under these conditions. For control slices, conditioning induced $38 \pm$ $5 \%$ LTP of S2 radiatum responses $(n=7$; Fig. $3 E)$. For primed slices, significantly less LTP was induced $(15 \pm 6 \%, n=5, p=$ 0.014). These results indicate that neither $\mathrm{GABA}_{\mathrm{A}}$ nor $\mathrm{GABA}_{\mathrm{B}}$ 
A

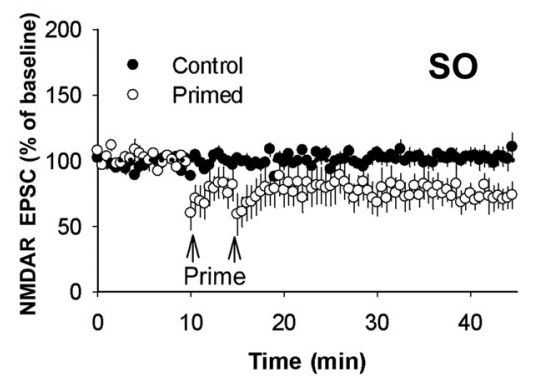

C

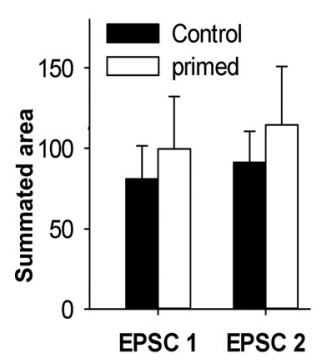

B

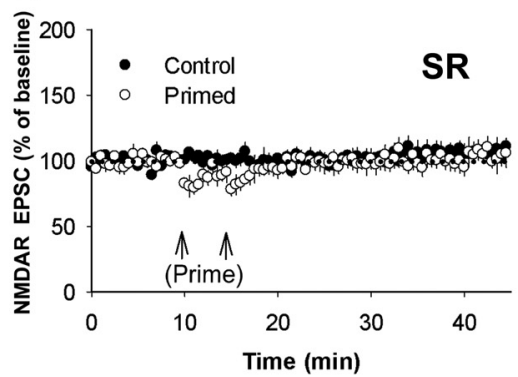

E

\section{D}

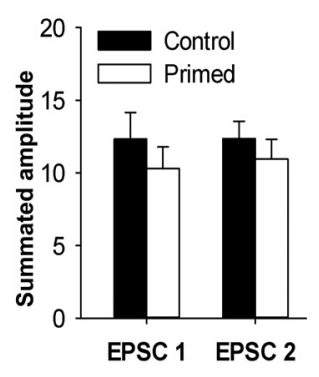

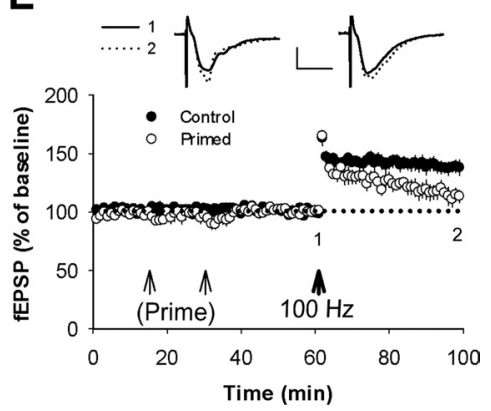

Figure 3. Expression of the metaplastic effect is not through altered NMDAR or GABAergic function. $\boldsymbol{A}$, Priming stimulation in stratum oriens reduced theNMDAREPSC evoked on the homosynaptic pathway (control, $103 \pm 7 \%, n=5$; primed, $73 \pm 8 \%, n=5$ ). $\boldsymbol{B}$, Therewas no change in the NMDAREPSC evoked on the heterosynaptic (stratum radiatum) pathway after oriens priming (control, $106 \pm 5 \%, n=5$; primed, $104 \pm 7 \%, n=6$ ). C, Summated NMDAR EPSC area expressed as a ratio of the average single EPSC recorded in the last 5 min of recording before $100 \mathrm{~Hz}$ tetanization. There was no difference in summated area between primed and control slices in either the response to the first or second HFS (First HFS: control, $81 \pm 16 \%, n=5$; primed $100 \pm 33 \%, n=5 ; p=0.62$; Second HFS: control, $91 \pm 15 \%$, primed, $114 \pm 36 \% ; p=0.57$ ). D, Summated NMDAR EPSC amplitude expressed as a ratio of the average single EPSC recorded in the last $5 \mathrm{~min}$ of recording before $100 \mathrm{~Hz}$ tetanization. There was no difference in summated amplitude between primed and control slices in either the response to the first or second HFS (First HFS: control, $12 \pm 1 \%, n=5$; primed, $10 \pm 1 \%, n=5 ; p=0.35$; Second HFS: control, $12 \pm$ $1 \%$, primed, $11 \pm 1 \% ; p=0.42$ ). $\boldsymbol{E}$, Blocking GABAergic transmission for the duration of the experiment did not prevent the inhibition of LTP following priming (control, $38 \pm 5 \%, n=7$; primed, $15 \pm 6 \%, n=5$ ). Insets, Representative waveforms are average of 5 synaptic responses before LTP induction (1) and at the conclusion of the experiment (2). Calibration: $0.5 \mathrm{mV}, 10 \mathrm{~ms}$.

receptors are involved in the induction or expression of the BCM-like metaplasticity.

Testing the role of postsynaptic cell firing

A critical element of the BCM model is that shifting of the modification threshold is determined by the time-averaged history of postsynaptic cell firing. Thus, we predicted that the induction of heterosynaptic metaplasticity in the present experiments would be mediated by somatic action potential firing in response to the priming stimulation. We tested this prediction using intracellular sharp electrode recording techniques. First, we demonstrated that the priming effect on LTP between two sets of radiatum synapses could be observed at the level of single cells, in the absence of any change in input resistance (Fig. $4 A$ ) or the amplitude of the peak AHP produced in response to LTP induction (control AHP: $7.64 \pm 0.85 \mathrm{mV}, n=10$; primed AHP: $6.73 \pm 0.88 \mathrm{mV}, n=12, p=0.448$ ). Surprisingly, however, we observed that the postsynaptic neuron fired very few action potentials during the 600 pulses of priming stimulation (mean 5 total spikes, range $0-12$ total spikes, $n=6$ cells), and the number of action potentials fired did not correlate with the degree of LTP inhibition (Pearson $r=-0.22 ; p=0.663$ ). The lack of firing is consistent with the generally weak depolarization generated under conditions of 100 $\mathrm{Hz}$ stimulation, whether as priming trains or conditioning trains (Fig. 1A, waveforms; mean 2.9 total spikes during the conditioning trains). These observations imply strongly that action potentials per se were not driving the metaplastic change. To test directly whether somatic action potentials during priming were necessary for the in- duction of priming in stratum radiatum, cells were hyperpolarized to a nominal $-100 \mathrm{mV}$ by manual application of negative holding current during priming stimulation to completely prevent cell firing. Despite this treatment, priming stimulation in stratum radiatum still significantly inhibited the degree of LTP $(26 \pm 9 \%)$ relative to control cells ( $54 \pm 8 \%, p=0.035$; Fig. $4 B$ ). Hyperpolarization during priming, however, did prevent the induction of LTP on the priming (homosynaptic) pathway (data not shown).

Although somatic action potentials and LTP on the priming pathway were blocked in the preceding experiment, the possible contribution of local action currents cannot be excluded. Thus, we repeated the experiment but applied priming stimulation to the stratum oriens. Somatic hyperpolarization in this case would completely prevent the conduction of membrane depolarization or action currents between the basal and apical dendritic compartments. Accordingly, cells were held at $-90 \mathrm{mV}$ during oriens priming. In these experiments both regular priming ( $25 \pm 5 \%, n=8$; data not shown) and priming during hyperpolarization (25 \pm $10 \%, n=8$ ) significantly inhibited LTP in radiatum compared with control LTP $(58 \pm$ $5 \%, n=8, p=0.002$; Fig. $4 C)$. Routine measurement of the peak AHP showed no change following either priming or conditioning in any group $\left(F_{(1.256,2.512)}=1.046, p=0.383\right)$. Likewise, no lasting changes were observed in input resistance (data not shown).

From the above experiments, we concluded that somatic action potentials are not necessary for the metaplasticity effect. Nonetheless, it remained conceivable that action potentials were sufficient to trigger the effect, as posited in the BCM model and has, with a reduced number of action potentials, been previously demonstrated to be sufficient under some conditions to inhibit subsequent LTP induction (Yasuda et al., 2003). To test this prediction, depolarizing current pulses of sufficient magnitude ( $2 \mathrm{nA}, 2 \mathrm{~ms})$ to regularly fire a single action potential per pulse were injected postsynaptically in the same pattern as the afferent stimulation normally given during the priming protocol. Of the 600 priming pulses, action potentials occurred in response to $\sim 70 \%$ of them, on average. Contrary to the prediction of reduced LTP following action potential firing, cells primed by depolarizing pulses showed a significantly enhanced LTP $(95 \pm 15 \% ; p=0.019 ;$ Fig. $4 B)$. These data demonstrate that somatic action potentials were neither necessary nor sufficient to produce heterosynaptic inhibition of LTP by priming stimulation, and thus represent a major departure from the assumption of the original BCM model.

Heterosynaptic metaplasticity is not mediated by NMDARs, mGluRs or L-type voltage-dependent calcium channels What other mechanisms besides action potentials could integrate the degree of prior activity as required for BCM-like metaplasticity? Derivatives of the BCM model have proposed a critical role for postsynaptic $\mathrm{Ca}^{2+}$ in this regard (Artola and Singer, 1993; Shouval et al., 2002b; Yeung et al., 2004). Although NMDARs 

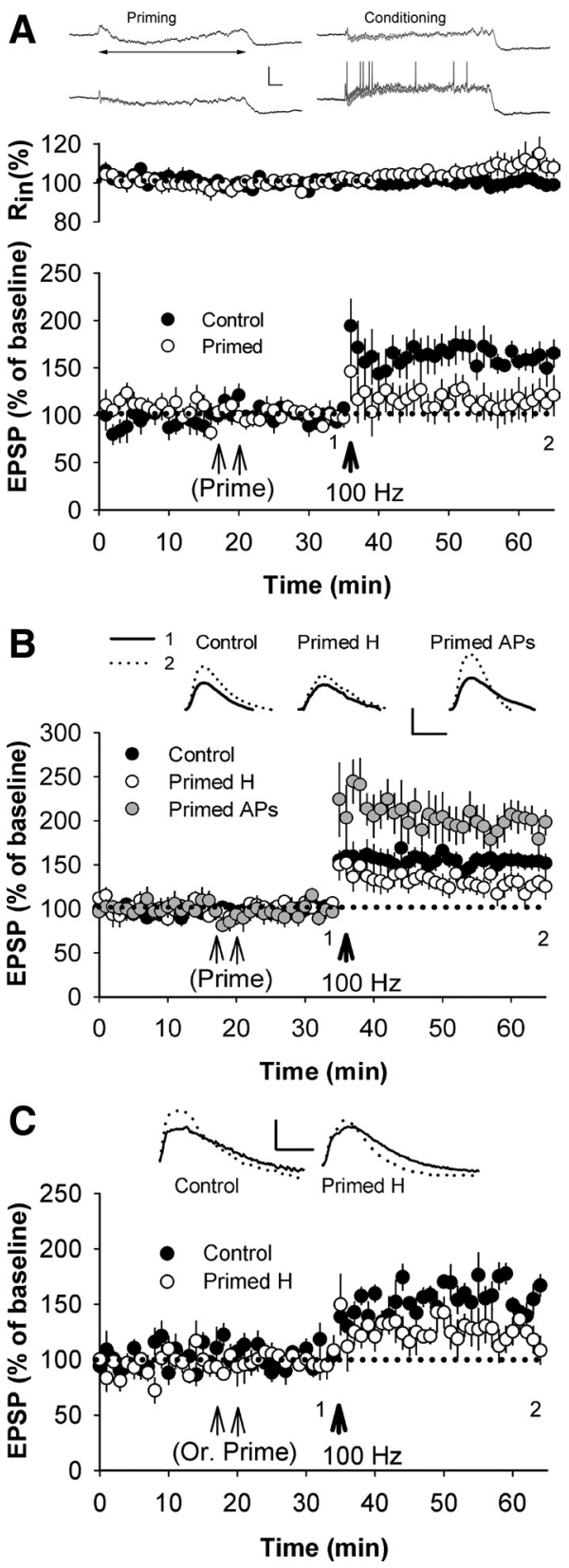

Figure 4. Cell-firing is neither necessary nor sufficient to inhibit LTP. A, Priming significantly inhibited LTP observed with intracellular recording (control, $59 \pm 9 \%, n=6$; primed, $14 \pm 17 \%, n=6 ; p=0.037$ ). Above graphs, Neither priming nor conditioning stimulation produced a change in input resistance (expressed as a percentage of prepriming baseline); in the last 5 min of recording there was no significant difference in input resistance changes between primed $(9 \pm 6 \%)$ and control groups $(0 \pm 2 \%, p=$ $0.187)$. Top panel waveforms are representative single traces from one cell showing the first two trains of each bout of priming, and from the two trains of conditioning stimulation. Note the relatively low level of depolarization in all cases, and lack of substantial postsynaptic spiking. Calibration: $10 \mathrm{mV}, 100 \mathrm{~ms}$. $\boldsymbol{B}$, Under control conditions ( $n=10)$, which included a period of hyperpolarization before HFS, $100 \mathrm{~Hz}$ stimulation induced stable LTP. Hyperpolarization to completely prevent action potentials during priming stimulation in stratum radiatum (Primed $\mathrm{H}, n=9$ ) did not prevent the subsequent inhibition of LTP. The delivery of action potentials, patterned according to the standard priming stimulation (Primed APs, $n=6$ ), facilitated subsequent LTP. C, Hyperpolarization to completely prevent action potentials during priming stimulation in stratum oriens (Primed $\mathrm{H}, n=8$ ) did not prevent the subsequent inhibition of LTP induced in stratum radiatum. Insets, Representative waveforms are the average of 10 synaptic responses before LTP induction (1) and at the conclusion of the experiment (2). Calibration: $5 \mathrm{mV}$, $10 \mathrm{~ms}$.
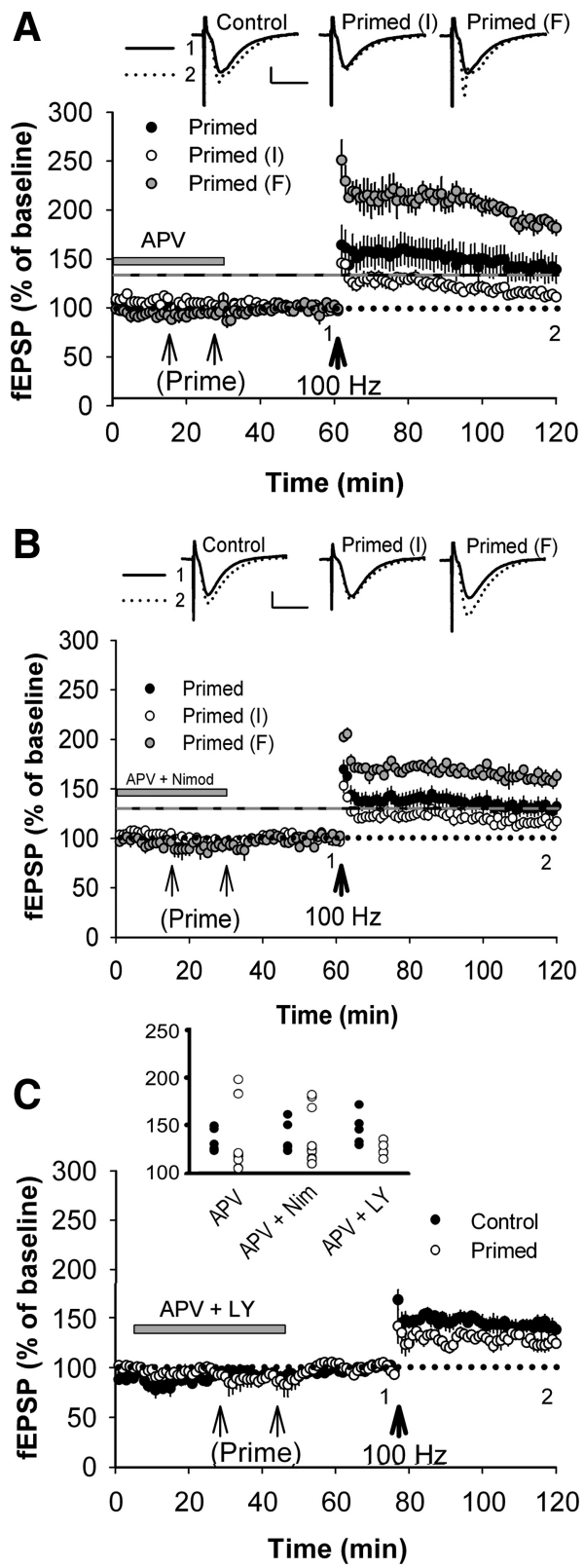

Figure 5. The inhibition of LTP is not dependent on NMDAR activation during priming. $\boldsymbol{A}$ Priming in the presence of D-APV (50 $\mu \mathrm{m}$, gray bar) resulted in most slices showing subsequently inhibited LTP [Primed (I), $n=6$ ], while a subset of slices showed dramatically facilitated LTP [Primed (F) $n=3$; control level of LTP (drug-treated as per primed slices) is shown by the black/gray dashed line, $n=7]$. $\boldsymbol{B}$, A similar result was observed when priming was given in the presence of D-APV ( $50 \mu \mathrm{M})$ and nimodipine (10 $\mu \mathrm{m}$, gray bar) with some slices showing subsequently inhibited LTP [Primed (I), $n=6$ ) and the same proportion as in $A$, showing facilitated LTP [Primed $(\boldsymbol{F}) n=3$; Control LTP, black/gray dashed line, $n=6$ ]. C, When priming was given in the presence of D-APV $(50 \mu \mathrm{M})$ and LY341495 $(100 \mu \mathrm{M})$, only inhibited LTP was observed (control, $n=5 ;$ primed, $n=5)$. Insets $(\boldsymbol{A}, \boldsymbol{B})$, Representative waveforms are average of 5 synaptic responses before LTP induction (1) and at the conclusion of the experiment (2). Calibration: $0.5 \mathrm{mV}, 10 \mathrm{~ms}$. Inset (C), Distribution of fEPSP potentiation expressed as a percentage of baseline, measured in the last 5 min of recording, for the D-APV, D-APV + Nimodipine, and D-APV + LY341495 conditions.

were considered the likely source of calcium, alternative sources were not excluded (Yeung et al., 2004). Given the ubiquitous nature of $\mathrm{Ca}^{2+}$ as a second messenger and the diverse number of ways in which rises in free intracellular $\mathrm{Ca}^{2+}$ can be produced, we tested various calcium sources as the mechanism mediating generation of the metaplastic state. 

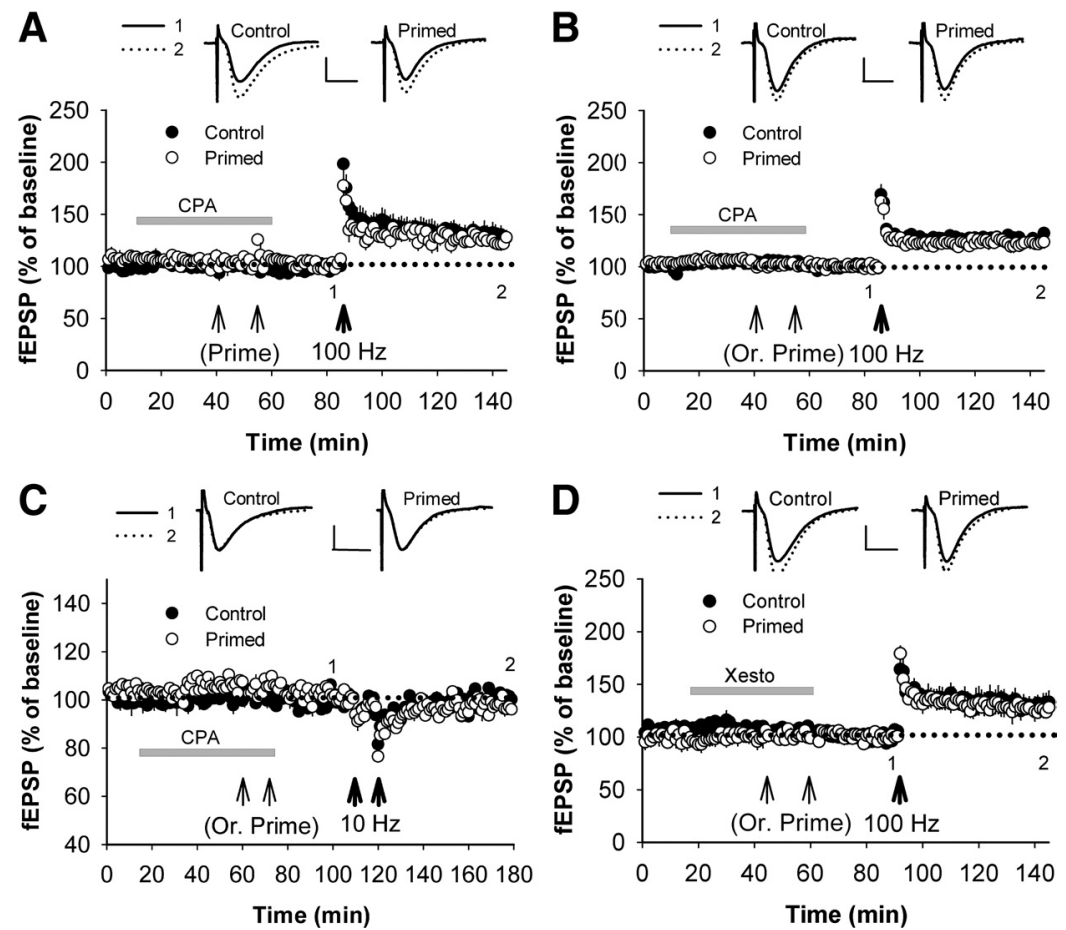

Figure 6. Dependence of priming on release of calcium from intracellular stores. $\boldsymbol{A}$, When priming stimulation was delivered in stratum radiatum in the presence of $50 \mu \mathrm{M}$ CPA (gray bar), there was no effect of priming on the level of subsequent LTP (control, $n=5$; primed, $n=5)$. $B$, The inhibition of LTP by priming stimulation in stratum oriens was also prevented by (PA (control, $n=$ 8 ; primed, $n=7$ ). C, The facilitation of LTD by oriens priming was also blocked by CPA (control, $1 \pm 1 \%, n=6$; primed, $-1 \pm$ $1 \%, n=6 ; p=0.11)$. $\boldsymbol{D}$, When priming stimulation was delivered in stratum radiatum in the presence of $3 \mu \mathrm{m}$ xestospongin $\mathrm{C}$ (Xesto, gray bar), there was no effect of priming on the level of subsequent LTP (control, $n=4$; primed, $n=4$ ). Insets, Representative waveforms are average of 5 synaptic responses before LTP induction (1) and at the conclusion of the experiment (2). Calibration: $0.5 \mathrm{mV}, 10 \mathrm{~ms}$.

To investigate the contribution of NMDARs, D-APV $(50 \mu \mathrm{M})$ was included in the ACSF from the beginning of the experiment, for both control and primed slices, and then washed out immediately following priming stimulation of stratum radiatum afferents (or at an equivalent time in control slices). In control slices, conditioning stimulation applied to the test pathway induced $35 \pm 5 \%$ LTP $(n=7$; Fig. $5 A$, black/gray dashed line). In the primed group, however, a mixed result was obtained: 6/9 slices showed inhibited LTP comparable to the level observed in Figure 1 (Primed (I): $14 \pm 3 \%, p=0.003$ when compared with control); however, $3 / 9$ slices showed dramatically facilitated LTP (Primed (F): $88 \pm 5 \%$; Fig. $5 A, C$ inset). The group average of these slices was not significantly different to control LTP $(38 \pm 13 \%, p=$ 0.84; Fig. 5A). Interestingly, no intermediate (control) levels of LTP were observed in the primed group (Fig. $5 C$ inset), which suggests that the inhibitory and facilitatory effects may be competitive. These results indicate that the inhibitory priming of LTP is probably not dependent on NMDAR activation during priming, although this conclusion is tempered by the observation that the presence of APV appears to allow some slices to show facilitated LTP. Note that in these experiments, LTP induction by the priming stimulation was completely blocked by APV (data not shown), indicating that the heterosynaptic priming effects are not dependent on the induction of homosynaptic LTP on the primed pathway.

Voltage-dependent calcium channels (VDCCs) are another major source of postsynaptic $\mathrm{Ca}^{2+}$ elevations in response to synaptic activity. One of the most prevalent postsynaptic VDCCs is the L-type channel which is present predominantly at the soma but is also expressed in dendrites (Christie et al., 1995; Magee and Johnston, 1995). Importantly, L-type VDCCs are critical for LTP induction in response to particularly high-frequency stimulation protocols (Grover, 1998; Freir and Herron, 2003). We considered it likely that VDCCs were activated by our high-frequency priming stimulation, and thus hypothesized that they could be an NMDARindependent source of calcium driving the metaplasticity effect. To test this hypothesis, we repeated the above experiment, but included the dihydropyridine L-type VDCC blocker nimodipine (10 $\mu \mathrm{M})$ with APV in the ACSF before and during priming. In control slices, conditioning induced $29 \pm 5 \%$ LTP $(n=6$; Fig. $5 B$, black/gray dashed line, $C$ inset). For primed slices, there was once again a bimodal LTP response. Inhibited LTP was observed in 6/9 slices (Primed (I): $15 \pm$ $2 \% ; p=0.045)$. However, $3 / 9$ slices again showed dramatically facilitated LTP (Primed (F): $61 \pm 3 \%$ ) and thus the group mean was not significantly different to control LTP ( $31 \pm 8 \%, p=0.85$; Fig. $5 B$ ). This pattern of results was similar to that seen in APV-only conditions, and demonstrates that L-type VDCC activation during priming does not mediate either the heterosynaptic inhibition of LTP or the facilitation of LTP that occurs in some slices exposed to APV.

Activation of Group I mGluRs can lead to elevations in free intracellular $\mathrm{Ca}^{2+}$ through triggering release from intracellular stores via a phospholipase $\mathrm{C} / \mathrm{G}_{\mathrm{q}}$-coupled pathway. Moreover mGluRs are critically involved in some types of metaplasticity (Bortolotto et al., 1994; Cohen et al., 1998, 1999; Mellentin and Abraham, 2001; Gisabella et al., 2003). To test the contribution of mGluRs to the present metaplasticity effect, the global mGluR antagonist LY341495 $(100 \mu \mathrm{M})$ was included with APV before and during the priming stimulation. In control slices, conditioning stimulation produced $37 \pm 6 \% \operatorname{LTP}(n=5$; Fig. $5 C)$. Primed slices showed a consistently inhibited LTP $(20 \pm 3 \%, n=5 ; p=$ 0.031). This demonstrates that heterosynaptic inhibition of LTP is not mediated by either mGluR or NMDAR activation during priming. It is notable that no primed facilitation was observed in the LY341495-treated slices, consistent with previous reports of Group I mGluR antagonists blocking primed facilitation of LTP (Cohen and Abraham, 1996; Cohen et al., 1998; Mellentin et al., 2007). Moreover, the priming effect was fully preserved in the face of a block of LTP on the primed pathway by APV/LY341495 (data not shown). Together, these results suggest that under normal (no drug) conditions, priming stimulation activates both NMDARs and mGluRs but that mGluR-mediated facilitation of LTP is prevented by the concurrent NMDAR activation. Most importantly, however, simultaneous block of both receptor types failed to prevent the inhibition of LTP by priming stimulation.

\section{Role of release of $\mathrm{Ca}^{2+}$ from intracellular stores}

An alternative mechanism for elevating intracellular $\mathrm{Ca}^{2+}$ could be the mobilization of $\mathrm{Ca}^{2+}$ from intracellular stores, which is the 
target of a number of signaling pathways in addition to Group I mGluRs. To test this possibility we used CPA $(50 \mu \mathrm{M})$, a reversible sarcoplasmic/endoplasmic reticulum $\mathrm{Ca}^{2+}$-ATPase pump inhibitor which, by preventing refilling, effectively empties the intracellular stores over a period of $30 \mathrm{~min}$ baseline stimulation (Seidler et al., 1989; Mellentin et al., 2007). In control slices given CPA plus washout, conditioning stimulation induced $31 \pm 8 \%$ LTP $(n=5$; Fig. $6 A)$. Priming stimulation in the presence of CPA had no significant effect on subsequent LTP $(28 \pm 3 \%, n=5, p=$ 0.672; Fig. $6 A$ ). There was also no difference between control and primed LTP when priming stimulation was given in stratum oriens in the presence of CPA (Fig. 6B). Finally, CPA also prevented facilitation of LTD by stratum oriens priming stimulation (Fig. 6C).

To determine whether the release of calcium from intracellular stores was mediated by $\mathrm{IP}_{3}$ or ryanodine receptor activation, we used the membrane-permeable $\mathrm{IP}_{3} \mathrm{R}$ blocker xestospongin $\mathrm{C}$. When priming stimulation was delivered to stratum oriens in the presence of $3 \mu \mathrm{M}$ xestospongin, there was no significant difference between control ( $28 \pm 8 \%, n=4$; Fig. $6 D)$ and primed ( $25 \pm 5 \%, n=4 ; p=0.80)$ levels of LTP. Together these results support the fundamental principle of calcium-focused derivatives of the BCM model by demonstrating that the metaplastic state is mediated by a calcium signal, in this case generated by $\mathrm{IP}_{3} \mathrm{R}$-mediated mobilization from intracellular stores.

\section{Muscarinic acetylcholine receptor activation is a trigger for heterosynaptic metaplasticity}

Having eliminated the most likely triggers for the mobilization of $\mathrm{Ca}^{2+}$ from intracellular stores (mGluRs, NMDARs and L-type VDCCs), we considered the alternative hypothesis that it was triggered instead by activation of $\mathrm{mAChRs}$ during priming stimulation, as these receptors are known to couple via $\mathrm{IP}_{3}$ to calcium release from the endoplasmic reticulum. In control slices given the $\mathrm{mAChR}$ antagonist atropine $(10 \mu \mathrm{M})$ followed by washout, conditioning stimulation induced $25 \pm 3 \% \operatorname{LTP}(n=6$; Fig. $7 A)$. When stratum oriens priming was given in the presence of atropine, the priming effect on LTP was blocked ( $28 \pm 9 \%, n=6, p=0.73)$. As atropine is a nonspecific AChR antagonist, we also used the specific m1-AChR antagonist pirenzepine. In control slices given pirenzipine $(20 \mu \mathrm{M})$ followed by washout, conditioning stimulation induced $23 \pm 4 \%$ LTP $(n=5$; Fig. $7 B)$. When oriens priming was given in the presence of pirenzipine, the priming effect on LTP was blocked ( $23 \pm 9 \%, n=$ $5, p=1.00)$.

\section{Discussion}

The BCM computational model of synaptic modification, originally designed to explain experience-dependent development of visual cortex synaptic organization (Bienenstock et al., 1982), has played a prominent role in conceptualizing the relation between different activity patterns and the resultant direction and degree of synaptic plasticity. Key features of the model are the biphasic plasticity induction function (the " $\phi$ " function) that relates the degree of correlated presynaptic and postsynaptic activity with the degree of LTD/LTP response, the cell-wide representation of the $\phi$ function, the homeostatic metaplastic control of the modification threshold, $\theta_{\mathrm{M}}$, and the ongoing role of postsynaptic cell firing in determining the position of $\theta_{\mathrm{M}}$. These specific features of the model have driven numerous experimental efforts to confirm them. For example, a $\phi$-type function has been described for both visual cortical and hippocampal excitatory synapses, typically through manipulation of the frequency of afferent synaptic activity, which is however only an indirect way of manipulating the degree of correlated presynaptic and postsynaptic activity as modeled by the BCM theory (Dudek and Bear, 1993;
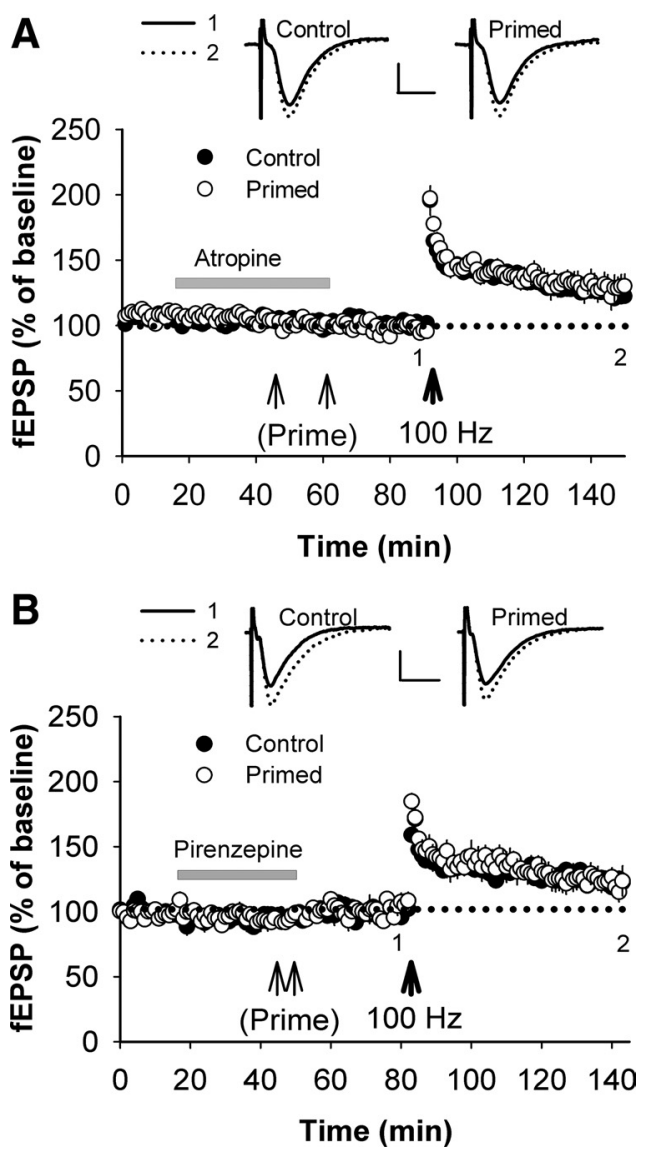

Figure 7. M1-AChR activation is required for priming. $\boldsymbol{A}$, When priming stimulation was delivered to stratum oriens in the presence of atropine (10 $\mu \mathrm{m}$, gray bar), there was no effect of priming on the level of LTP (control, $n=6$; primed, $n=6$ ). $B$, The effect of priming stimulation on LTP was also prevented by the specific M1-AChR antagonist pirenzepine ( $20 \mu \mathrm{m}$; control, $n=5$; primed, $n=5$ ). Insets, Representative waveforms are averages of 5 synaptic responses before LTP induction (1) and at the conclusion of the experiment (2). Calibration: $0.5 \mathrm{mV}, 10 \mathrm{~ms}$.

Kirkwood et al., 1996; Philpot et al., 2003, 2007; but see also Ngezahayo et al., 2000). Furthermore, the modification threshold has been reported to shift in an activity-dependent fashion, through for example dark-rearing in the case of visual cortex synapses, or afferent stimulation in the case of hippocampal synapses (Wang and Wagner, 1999; Abraham et al., 2001). In the latter case, the use of afferent priming stimulation has allowed tests that confirm that increased afferent activity can drive $\theta_{\mathrm{M}}$ to the right of the $\phi$ function not only for the stimulated synapses, but also heterosynaptically for neighboring quiescent synapses, in accord with the BCM postulate of a cell-wide sliding modification threshold. We have replicated and extended these findings by showing in the hippocampal CA1 model that synaptic activity in the basilar dendrites can affect the $\phi$ function even at synapses terminating on dendrites located on the opposite side of the cell body. Interestingly, the metaplastic state induced by apical dendrite stimulation did not extend to the basilar dendrites, revealing a site-specific compartmentalization of the effect.

\section{Lack of a role for action potentials in \\ heterosynaptic metaplasticity}

A critical prediction of the $\mathrm{BCM}$ model that has resisted direct testing in previous studies is that postsynaptic action potentials mediate changes in $\theta_{\mathrm{M}}$. While recent derivatives of the BCM model have focused more on calcium signals as the activity "integrator," such signals could still be dependent on back-propagating action poten- 
tials that open voltage-gated calcium channels (Spruston et al., 1995; Stuart et al., 1997; Yasuda et al., 2003). Some studies have reported that chronic infusions of the $\mathrm{GABA}_{\mathrm{A}}$ receptor agonist muscimol during monocular deprivation block the ocular dominance plasticity that normally occurs in visual cortex (Reiter and Stryker, 1988; Frank et al., 2006). Such treatments, however, will affect any depolarization-mediated events, and so will not be selective for action potentials per se. In the hippocampus, we reported that antidromic activation of dentate granule cells in vivo could inhibit LTP induction in lateral perforant path synapses for days (Abraham et al., 2001). However, the use of field potential recording techniques precluded a definitive conclusion regarding the role of postsynaptic action potentials.

Here, we took advantage of the CA1 slice as a tractable experimental preparation for investigating the necessity and sufficiency of postsynaptic action potential firing using single neuron recordings. We found that cell firing was neither necessary nor sufficient for integrating the neural activity driving heterosynaptic metaplasticity in this preparation. Indeed, firing postsynaptic action potentials actually facilitated subsequent LTP, supporting previous findings of Dudek and Fields (2002). Instead, the metaplasticity was dependent on a calcium signal arising from intracellular stores. This signal mediated not only radiatum-radiatum interactions, but also the longrange interactions from stratum oriens to stratum radiatum. Thus, our evidence provides the first direct support for the calciumfocused versions of the BCM model, and specifically rules out a critical role of either postsynaptic action potentials or NMDAR activation in governing $\theta_{\mathrm{M}}$, at least in CA1.

\section{Comparison with other models of heterosynaptic modulation of plasticity}

The heterosynaptic inhibition of LTP by priming stimulation, observed in the present study as well as others (Wang and Wagner, 1999; Abraham et al., 2001), contrasts with the heterosynaptic upregulation of LTP persistence revealed by synaptic tag and capture experiments (Frey and Morris, 1997, 1998a,b). In these latter experiments, a weak decremental LTP is converted into a long-lasting protein synthesis-dependent LTP if a strong heterosynaptic HFS that activates protein synthesis is given shortly before or after the induction of the weak LTP. In the present experiments, in contrast, the strong priming stimulation should have easily been sufficient to increase protein synthesis, yet it strongly inhibited LTP on the test pathway. One explanation for these conflicting findings could rest on the fact that the stimulation for generating weak LTP is set well below the threshold for activating protein synthesis, commonly involving only a single train of $\sim 20$ pulses (Frey and Morris, 1997). In the present experiment, a stronger HFS paradigm was used for the test pathway (typically 200 pulses). Thus there appears to be a complexity of heterosynaptic interactions operating at CA1 synapses such that very weak synaptic potentiation can benefit from capture of newly synthesized proteins, while induction of a stronger LTP is impaired by prior intense activation of other synapses.

Our findings also contrast with previous studies of competitive interactions between pathways for LTP resources. For example, Fonseca et al. (2004) showed that LTP induction on one pathway could impair maintenance of prior LTP on a second pathway, presumably by competing for scarce raw materials required for LTP expression as caused by partial inhibition of protein synthesis. Subsequently it was shown that widespread saturation of LTP can inhibit subsequent LTP on a second nearby pathway (Roth-Alpermann et al., 2006). In our experiments, however, no LTP needed to be generated on the priming pathway in order for LTP to be inhibited on the test pathway (see APV and hyperpolarization experiments). Moreover, the degree of LTP in the primed pathway, when it did occur, did not correlate with the degree of LTP inhibition. Thus the heterosynaptic metaplasticity in the present model was completely independent of prior LTP induction at the priming synapses. These data are consistent with a more regulated homeostasis of synaptic plasticity as prescribed by the BCM model, which helps preserve plasticity capability in the face of large-scale changes in afferent activity.

\section{Expression mechanisms of heterosynaptic metaplasticity}

The expression mechanism ultimately responsible for the altered LTP/LTD remains elusive. The effect was not due to altered $\mathrm{GABA}_{\mathrm{A}}$ receptor-mediated synaptic inhibition, nor could we find evidence for a change in basal membrane properties, in contrast to other metaplasticity reports (Cohen et al., 1999; Le Ray et al., 2004). We also considered the possibility that priming stimulation might lead to a cell-wide change in NMDAR activation. However, voltage-clamp recordings revealed that while priming stimulation did cause an LTD of NMDAR-mediated currents in the primed synapses, heterosynaptically there was no change in the single or summated NMDAR current amplitudes or waveshapes (Xu et al., 2009; Lee et al., 2010). This leads us to conclude that the mechanism probably involves alteration in molecules downstream from membrane depolarization and NMDAR activation that are responsible for the decreased LTP and facilitated LTD.

Overall, our findings provide strong support for hippocampal CA1 exhibiting a novel form of heterosynaptic interactions between inputs. On the one hand, it is BCM-like in that high levels of activity at some inputs can reduce LTP and enhance LTD at other synapses spread widely across the cell (Wang and Wagner, 1999; Abraham et al., 2001; Fonseca et al., 2004). On the other hand, this form of heterosynaptic metaplasticity diverges from the computational models in (1) being compartmentally restricted when priming stimulation is delivered to afferents in stratum radiatum, (2) being independent of postsynaptic action potentials in the affected cell, and (3) being driven by muscarinic rather than glutamatergic receptor activation. Activation of muscarinic receptors elevates intracellular concentrations of calcium in both neurons and glia in the hippocampus (Egorov and Müller, 1999; Beier and Barish, 2000; Araque et al., 2002; Perea and Araque, 2005), and it will require additional approaches to determine which cell types and signaling pathways mediate the metaplasticity effects. Regardless, these experiments raise the question whether BCM-like metaplasticity in other brain regions such as visual cortex involve mechanisms similar to those shown here for the hippocampus. Indeed, muscarinic receptor activation can regulate concurrently induced synaptic plasticity in visual cortex, as in hippocampus (Huang et al., 2012; Kirkwood et al., 1999; Seol et al., 2007), and therefore it may serve an important metaplasticity function there as well. However, it remains important to directly test whether BCM-like metaplasticity responses to severe and prolonged changes in synaptic input, such as darkrearing or eyelid closure, involves action potential-dependent mechanisms as proposed in the computational models.

\section{References}

Abraham WC (2008) Metaplasticity: tuning synapses and networks for plasticity. Nat Rev Neurosci 9:387.

Abraham WC, Bear MF (1996) Metaplasticity: the plasticity of synaptic plasticity. Trends Neurosci 19:126-130.

Abraham WC, Mason-Parker SE, Bear MF, Webb S, Tate WP (2001) Heterosynaptic metaplasticity in the hippocampus in vivo: a BCM-like modifiable threshold for LTP. Proc Natl Acad Sci U S A 98:10924-10929. 
Araque A, Martín ED, Perea G, Arellano JI, Buño W (2002) Synaptically released acetylcholine evokes $\mathrm{Ca}^{2+}$ elevations in astrocytes in hippocampal slices. J Neurosci 22:2443-2450.

Artola A, Singer W (1993) Long-term depression of excitatory synaptic transmission and its relationship to long-term potentiation. Trends Neurosci 16:480-487.

Beier SM, Barish ME (2000) Cholinergic stimulation enhances cytosolic calcium ion accumulation in mouse hippocampal CA1 pyramidal neurones during short action potential trains. J Physiol 526:129-142.

Benuskova L, Abraham WC (2007) STDP rule endowed with the BCM sliding threshold accounts for hippocampal heterosynaptic plasticity. J Comput Neurosci 22:129-133.

Benusková L, Diamond ME, Ebner FF (1994) Dynamic synaptic modification threshold: computational model of experience-dependent plasticity in adult rat barrel cortex. Proc Natl Acad Sci U S A 91:4791-4795.

Bienenstock EL, Cooper LN, Munro PW (1982) Theory for the development of neuron selectivity: orientation specificity and binocular interaction in visual cortex. J Neurosci 2:32-48.

Bortolotto ZA, Bashir ZI, Davies CH, Collingridge GL (1994) A molecular switch activated by metabotropic glutamate receptors regulates induction of long-term potentiation. Nature 368:740-743.

Chevaleyre V, Castillo PE (2004) Endocannabinoid-mediated metaplasticity in the hippocampus. Neuron 43:871-881.

Christie BR, Stellwagen D, Abraham WC (1995) Reduction of the threshold for long-term potentiation by prior theta-frequency synaptic activity. Hippocampus 5:52-59.

Cohen AS, Abraham WC (1996) Facilitation of long-term potentiation by prior activation of metabotropic glutamate receptors. J Neurophysiol 76:953-962.

Cohen AS, Raymond CR, Abraham WC (1998) Priming of long-term potentiation induced by activation of metabotropic glutamate receptors coupled to phospholipase C. Hippocampus 8:160-170.

Cohen AS, Coussens CM, Raymond CR, Abraham WC (1999) Long-lasting increase in cellular excitability associated with the priming of LTP induction in rat hippocampus. J Neurophysiol 82:3139-3148.

Dudek SM, Bear MF (1993) Bidirectional long-term modification of synaptic effectiveness in the adult and immature hippocampus. J Neurosci 13:2910-2918.

Dudek SM, Fields RD (2002) Somatic action potentials are sufficient for late-phase LTP-related cell signalling. Proc Natl Acad Sci U S A 99:39623967.

Egorov AV, Müller W (1999) Subcellular muscarinic enhancement of excitability and $\mathrm{Ca}^{2+}$-signals in CA1-dendrites in rat hippocampal slice. Neurosci Lett 261:77-80.

Fonseca R, Nägerl UV, Morris RG, Bonhoeffer T (2004) Competing for memory: hippocampal LTP under regimes of reduced protein synthesis. Neuron 44:1011-1020.

Frank MG, Jha SK, Coleman T (2006) Blockade of postsynaptic activity in sleep inhibits developmental plasticity in visual cortex. Neuroreport 17:1459-1463.

Freir DB, Herron CE (2003) Inhibition of L-type voltage dependent calcium channels causes impairment of long-term potentiation in the hippocampal CA1 region in vivo. Brain Res 967:27-36.

Frey U, Morris RG (1997) Synaptic tagging and long-term potentiation. Nature 385:533-536.

Frey U, Morris RG (1998a) Weak before strong: dissociating synaptic tagging and plasticity-factor accounts of late-LTP. Neuropharmacology 37:545-552

Frey U, Morris RG (1998b) Synaptic tagging: implications for late maintenance of hippocampal long-term potentiation. Trends Neurosci 21:181-188.

Gisabella B, Rowan MJ, Anwyl R (2003) Mechanisms underlying the inhibition of long-term potentiation by preconditioning stimulation in the hippocampus in vitro. Neuroscience 121:297-305.

Gold JI, Bear MF (1994) A model of dendritic spine $\mathrm{Ca}^{2+}$ concentration exploring possible bases for a sliding synaptic modification threshold. Proc Natl Acad Sci U S A 91:3941-3945.

Grossman AW, Churchill JD, Bates KE, Kleim JA, Greenough WT (2002) A brain adaptation view of plasticity: is synaptic plasticity an overly limited concept? Prog Brain Res 138:91-108.

Grover LM (1998) Evidence for postsynaptic induction and expression of NMDA receptor independent LTP. J Neurophysiol 79:1167-1182.
Huang S, Treviño M, He K, Ardiles A, de Pasquale R, Guo Y, Palacios A, Huganir R, Kirkwood A (2012) Pull-push neuromodulation of LTP and LTD enables bidirectional experience-induced synaptic scaling in visual cortex. Neuron 73:497-510.

Ireland DR, Abraham WC (2009) Mechanisms of group I mGluR-dependent long-term depression of NMDA receptor-mediated transmission at Schaffer collateral-CA1 synapses. J Neurophysiol 101:1375-1385.

Kirkwood A, Rioult MC, Bear MF (1996) Experience-dependent modification of synaptic plasticity in visual cortex. Nature 381:526-528.

Kirkwood A, Rozas C, Kirkwood J, Perez F, Bear MF (1999) Modulation of long-term synaptic depression in visual cortex by acetylcholine and norepinephrine. J Neurosci 19:1599-1609.

Le Ray D, Fernández De Sevilla D, Belén Porto A, Fuenzalida M, Buño W (2004) Heterosynaptic metaplastic regulation of synaptic efficacy in CA1 pyramidal neurons of rat hippocampus. Hippocampus 14:1011-1025.

Lee MC, Yasuda R, Ehlers MD (2010) Metaplasticity at single glutamatergic synapses. Neuron 66:859-870.

Magee JC, Johnston D (1995) Synaptic activation of voltage-gated channels in the dendrites of hippocampal pyramidal neurons. Science 268: 301-304.

Mellentin C, Abraham WC (2001) Priming stimulation of group II metabotropic glutamate receptors inhibits the subsequent induction of rat hippocampal long-term depression in vitro. Neurosci Lett 307:13-16.

Mellentin C, Jahnsen H, Abraham WC (2007) Priming of long-term potentiation mediated by ryanodine receptor activation in rat hippocampal slices. Neuropharmacology 52:118-125.

Ngezahayo A, Schachner M, Artola A (2000) Synaptic activity modulates the induction of bidirectional synaptic changes in adult mouse hippocampus. J Neurosci 20:2451-2458.

Perea G, Araque A (2005) Properties of synaptically evoked astrocyte calcium signal reveal synaptic information processing by astrocytes. J Neurosci 25:2192-2203.

Philpot BD, Espinosa JS, Bear MF (2003) Evidence for altered NMDA receptor function as a basis for metaplasticity in visual cortex. J Neurosci 23:5583-5588.

Philpot BD, Cho KK, Bear MF (2007) Obligatory role of NR2A for metaplasticity in visual cortex. Neuron 53:495-502.

Reiter HO, Stryker MP (1988) Neural plasticity without postsynaptic action potentials: less-active inputs become dominant when kitten visual cortical cells are pharmacologically inhibited. Proc Natl Acad Sci U S A 85: 3623-3627.

Roth-Alpermann C, Morris RG, Korte M, Bonhoeffer T (2006) Homeostatic shutdown of long-term potentiation in the adult hippocampus. Proc Natl Acad Sci U S A 103:11039-11044.

Seidler NW, Jona I, Vegh M, Martonosi A (1989) Cyclopiazonic acid is a specific inhibitor of the $\mathrm{Ca}^{2+}$-ATPase of sarcoplasmic reticulum. J Biol Chem 264:17816-17823.

Seol GH, Ziburkus J, Huang S, Song L, Kim IT, Takamiya K, Huganir RL, Lee HK, Kirkwood A (2007) Neuromodulators control the polarity of spiketiming-dependent synaptic plasticity. Neuron 55:919-929.

Shouval HZ, Bear MF, Cooper LN (2002a) A unified model of NMDA receptor-dependent bidirectional synaptic plasticity. Proc Natl Acad Sci U S A 99:10831-10836.

Shouval HZ, Castellani GC, Blais BS, Yeung LC, Cooper LN (2002b) Converging evidence for a simplified biophysical model of synaptic plasticity. Biol Cybern 87:383-391.

Spruston N, Schiller Y, Stuart G, Sakmann B (1995) Activity-dependent action potential invasion and calcium influx into hippocampal CA1 dendrites. Science 268:297-300.

Stuart G, Spruston N, Sakmann B, Häusser M (1997) Action potential initiation and backpropagation in neurons of the mammalian CNS. Trends Neurosci 20:125-131

Wang H, Wagner JJ (1999) Priming-induced shift in synaptic plasticity in the rat hippocampus. J Neurophysiol 82:2024-2028.

Xu Z, Chen RQ, Gu QH, Yan JZ, Wang SH, Liu SY, Lu W (2009) Metaplastic regulation of long-term potentiation/long-term depression threshold by activity-dependent changes of NR2A/NR2B ratio. J Neurosci 29:87648773.

Yasuda R, Sabatini BL, Svoboda K (2003) Plasticity of calcium channels in dendritic spines. Nat Neurosci 6:948-955.

Yeung LC, Shouval HZ, Blais BS, Cooper LN (2004) Synaptic homeostasis and input selectivity follow from a calcium-dependent plasticity model. Proc Natl Acad Sci U S A 101:14943-14948. 